\title{
STUDIES ON GANGRENE FOLLOWING COLD INJURY. V. THE USE OF FLUORESCEIN AS AN INDICATOR OF LOCAL BLOOD FLOW : FLUORESCEIN TESTS IN EXPERIMENTAL FROSTBITE ${ }^{1}$
}

\author{
By J. M. CRISMON AND FREDERICK A. FUHRMAN \\ (From the Department of Physiology, Stanford University School of Medicine, \\ Stanford University, California)
}

(Received for publication September 1, 1946)

The application of the fluorescein test to the study of frostbite has been described recently by Lange and Boyd (1). In the course of studies of experimental frostbite carried on in this laboratory, certain of the results obtained with the fluorescein test have been difficult to explain on the basis of interpretations suggested by the proposers of the method. Two groups of experiments were undertaken in order to study certain aspects of fluorescein exchange not already reported in the literature. The first group of experiments consisted of studies on normal rabbits of skin fluorescence and fluorescein distribution in body fluids : these have been presented previously (2). The present paper reports the second group of studies carried out on normal rabbits and on rabbits subjected to severe cold injury.

\section{METHOD}

The techniques employed in the fluorescein test, the measurement of skin fluorescence after the injection of fluorescein, and the analysis of body fluids for fluorescein were described previously (2). Skin fluorescence under ultraviolet light was photographed with a Kodak Recomar having a Kodak anastigmat lens, f. 4.5 of $105 \mathrm{~mm}$. focal length. Black and white photographs were taken at $\mathrm{f} .8$ on Ansco Superpan Press film with exposure times of 15 seconds through a Wratten No. 15 filter or 90 seconds through a Wratten No. 62 filter. The animals used in all of the experiments were adult New Zealand white rabbits from a uniform strain.

\section{RESULTS}

\section{Fluorescence in normal skin}

When the intravenous injection of fluorescein was made while the animals were exposed to ultraviolet light, bright greenish-yellow fluores-

\footnotetext{
1 The work described in this paper was done under a contract, recommended by the Committee on Medical Research, between the Office of Scientific Research and Development and Stanford University.
}

cence was detectable in hair-free areas of the skin within a few seconds after the beginning of injection. The intensity of color became maximal in about 15 minutes. The decline of intensity was, at first, rapid and then progressively more gradual over a period of 2 to $2 \frac{1}{2}$. hours. In the rabbit ear, the regions which glowed most intensely were those relatively free of large blood vessels. The larger blood vessels stood out as dark streaks which could be obliterated by prescure with a glass slide. The areas rendered ischemic by pressure showed no decrease of fluorescence.

\section{Fuorescence in frostbitten ears of rabbits}

The influence of injury by frostbite upon the distribution of fluorescein after intravenous injection was studied on rabbits' ears. Frostbite was produced by immersing the distal 3 to 4 $\mathrm{cm}$. of the ears in a freezing mixture consisting of alcohol, ethylene glycol, and water with sufficient solid carbon dioxide added to bring the temperature between $-52^{\circ} \mathrm{C}$. and $-70^{\circ} \mathrm{C}$. The details of the method of producing standard cold injury and the general course of changes following such injuries have been described in previous reports $(3,4)$.

Abnormalities in the distribution of fluorescein in the frostbitten portion of rabbits' ears included decreased rate of entrance of dye, slower rate of removal, and lower maximum intensity of fluorescence than was observed in the normal ear. Observations made at varying intervals after injury showed that the local changes, which were responsible for the abnormalities of fluorescein distribution, undergo modification with time. The photographs in Figure 1 illustrate the delayed penetration and exit of the dye as well as the differences in results of identical tests made immediately after inquiry and repeated 
some 18 hours later. Figure $1 \mathrm{~A}$ shows a photograph of the normal ear of a rabbit taken under ultraviolet light before the injection of fluorescein and before the ear was frostbitten. The small bright spot near the tip of the ear is the fluorescence from a drop of lubricating oil which was smeared on the skin from the electric clipper. Figure $1 \mathrm{~B}$ was taken 15 minutes after the ear was re-
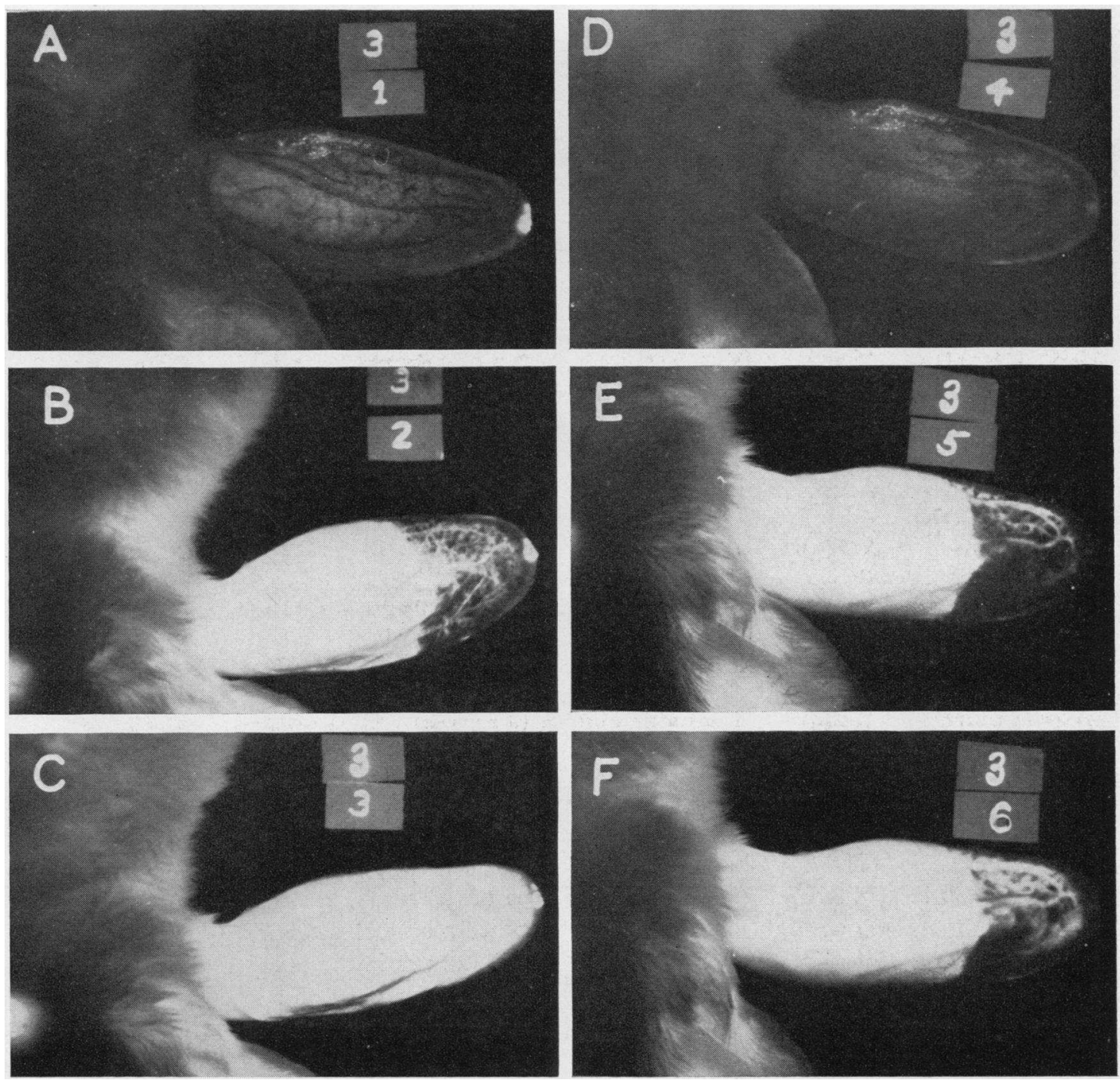

Fig. 1. Distribution of Fluorescein in a Frostbitten Rabbit Ear at Varying Times after Injury ANd AFTER Fluorescein INJECTION

A. Normal ear under ultraviolet light before frostbite, and before injection of fluorescein.

B. 15 minutes after frostbite $\left(1\right.$-minute immersion at $-70^{\circ} \mathrm{C}$.) and 10 minutes after injection of $75 \mathrm{mgm}$. per $\mathrm{kgm}$. sodium fluorescein into the marginal ear vein of the opposite ear.

C. 30 minutes after frostbite and 25 minutes after fluorescein.

D. 18 hours 30 minutes after frostbite. Fluorescein completely removed.

E. 18 hours 50 minutes after frostbite and 10 minutes after a second intravenous. injection of fluorescein.

F. 19 hours 5 minutes after frostbite and 25 minutes after the second fluorescein injection.

Photographs taken with ultraviolet light from an HGCH4 lamp. Lamp filters consisted of a heat resisting red-purple and a LV blue-purple glass filter. Lens filter was Wratten No. 15. Exposure 15 seconds at $\mathrm{f} .8$ on Ansco Superpan Press film. 


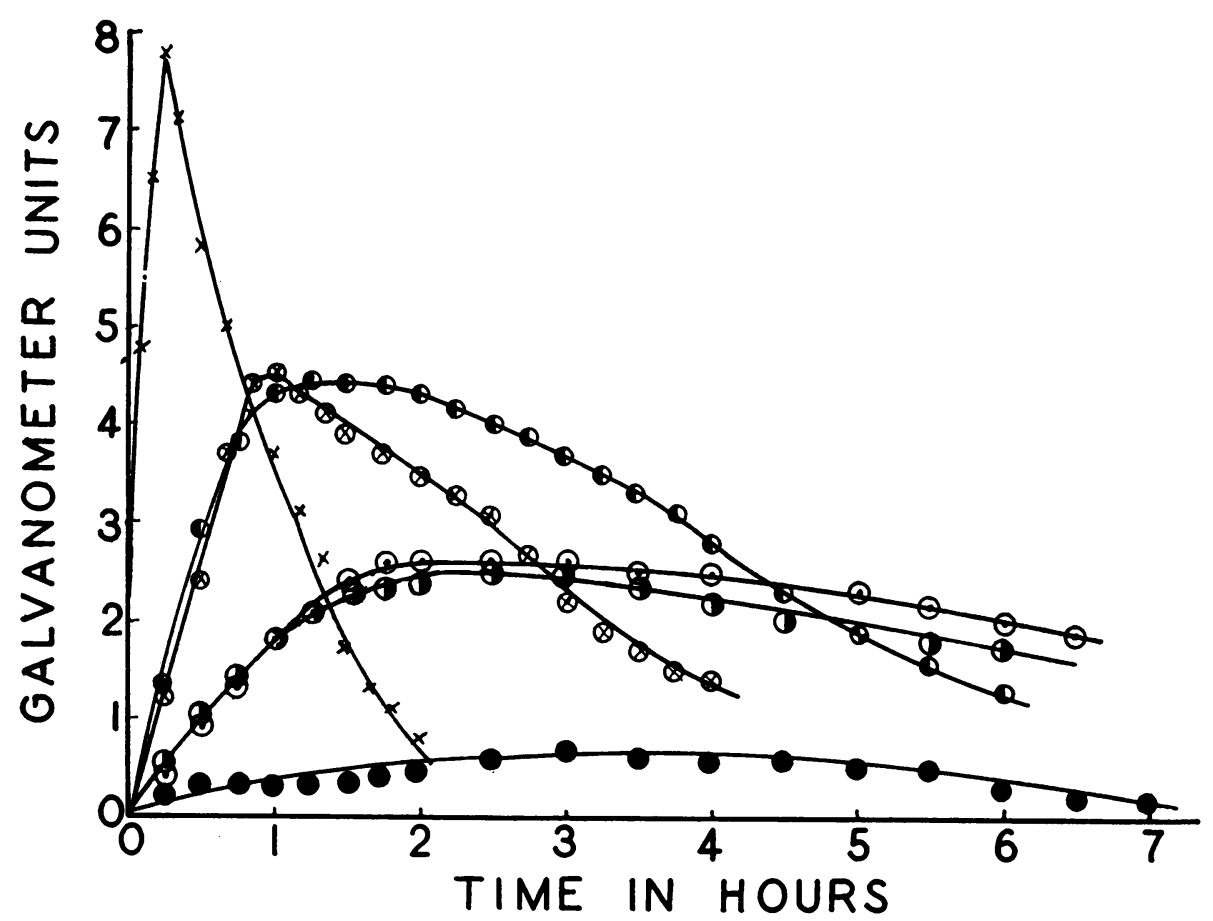

Fig. 2. Intexity of Fllorescence of Rabbits' Ears at Different Time Perions AFter Frostbite

Ears exposed at $-55^{\circ}$ C. for 90 seconds. Fluorescein injected at zero time.

$\times$ Normal ears (6 animals) Immediately after frostbite (5 animals)

- 1 hour after frostbite ( 4 animals) 1 day after frostbite ( 3 animals)

- 2 days after frostbite (3 animals) 3 days after frostbite ( 2 animals)

moved from the freezing mixture. The exposure to cold was 1 minute at $-70^{\circ} \mathrm{C} .{ }^{2}$ Fluorescein was injected intravenously in the opposite ear $10 \mathrm{~min}$ utes before the photograph was taken. The depth of immersion in the freezing mixture is clearly indicated by the virtual absence of fluorescence in the distal $3 \mathrm{~cm}$. of the ear. The larger vessels of the distal part of the ear are faintly fluorescent at this time, with an appreciable spread of dye about the central artery for a distance of about $8 \mathrm{~mm}$. into the injured area. Some lack of sharpness in the junction between the brightly fluorescent, normal part and the injured region suggests that limited penetration of fluorescein was taking place at that point. Figure $1 \mathrm{C}$ is a photograph of the same animal taken 30 minutes after frostbite and 25 minutes after the injection of dye. It will be

2 The results were the same when the temperature of the freezing mixture was $-52^{\circ}$ to $-56^{\circ} \mathrm{C}$. noted that the intensity of fluorescence had diminished to a considerable degree in the normal part of the ear, while that in the injured area had reached a brightness almost equal to that observed at 10 minutes in the uninjured areas, and that the fluorescence almost obscures vascular detail. Figure $1 \mathrm{D}$, photographed $18 \mathrm{r} / 2$ hours after the first injection of fluorescein, shows the complete removal of dye from all parts of the ear at that time. Figure $1 \mathrm{E}$ illustrates the appearance of the ear at 18 hours and 50 minutes after frostbite and 10 minutes after the second injection of fluorescein. In this photograph the vascular detail, which was easily made out in the normal part of the ear at 10 minutes after the first injection of dye, is almost completely obscured by the massive edema and the distribution of fluorescein in the skin. The penetration of dye into the injured region can be seen only faintly outlining the major vascular 
channels. Figure 1F, photographed 25 minutes after the second injection of fluorescein, shows a striking reduction in the amount of dye in the injured region as compared with the amount which accumulated during an identical interval after injection when the injury was only 30 minutes old.

\section{Time intensity relationships of fluorescence in normal and frostbitten ears of rabbits}

Photoelectric measurements were made of the change in intensity with time of fluorescence in 6 normal rabbit ears and in 17 ears at various times after frostbite. Figure 2 shows the results of these measurements in curves plotted with the intensity of fluorescence on the axis of ordinates in terms of galvanometer units and time in hours after the injection of fluorescein on the axis of abscissas. In normal ears, the change in itensity of fluorescence with time was characterized by a very rapid rise to a maximum within 15 minutes and a somewhat less rapid decline in intensity, with final disappearance of glow occurring between 2 and 3 hours after injection of dye. The rate of increase in intensity measured in frostbitten ears when the dye was injected immediately or at 1 hour after injury is slower than that observed in normal ears. When the injection of fluorescein was made at sucsessively longer intervals after frostbite, further slowing of both the entrance and exit of dye occurred. At intervals of 1 and 2 days after frostbite the maximum intensity reached was only a little over a third of that reached in normal ears. The tendency for exit of fluorescein from the frostbitten region to be slower than its entrance, a phenomenon noticeable in the comparison between measurements made when the dye was injected immediately after frostbite with those made at 1 hour, was greatly exaggerated in the tests made at intervals of 1 and 2 days. While no striking differences were noticeable between the measurements made on the first and second days after injury,.the tests on the third day showed only a feeble fluorescence. The maximum occurred about 2 hours after the injection of dye and was followed by a greatly prolonged course of removal. In some cases fluorescence was detected by direct observation as long as 24 hours after dye injection.

Since the rates of entrance and removal of dye were shown to become progressively slower as the interval between injury and the test was increased, only the earliest tests were subjected to statistical comparison. The significance of difference in rates of fluorescein exchange between that in normal ears and that in ears tested immediately after frostbite was calculated (5). Table I presents measurements of fluorescence at 10 minutes after the injection of dye and at 2 hours after injection in 5 normal ears and in 5 frostbitten ears of rabbits receiving fluorescein immediately after frostbite. Comparison of the intensity of fluorescence in both series at 10 minutes after injection shows that the brilliance is significantly greater in normal ears. Analysis at this time interval was considered to be free of differences which might be attributed to gross deficiencies of blood flow in the frostbitten ears because skin temperature measurements taken at this time showed that the temperature was rising very rapidly. The pink color of the skin and the large size of major blood

TABLE I

Measurements of intensity of fuorescence in normal and frostbitten ears of rabbits at intervals after injection of fluorescein

Data from 5 animals

\begin{tabular}{|c|c|c|c|c|c|c|c|c|}
\hline \multirow{4}{*}{ Column } & \multicolumn{4}{|c|}{ Normal ears } & \multicolumn{4}{|c|}{$\begin{array}{l}\text { Frostbitten ears } 90 \text {-second } \\
\text { exposure at }-55^{\circ} \mathrm{C} \text {. }\end{array}$} \\
\hline & 1 & 2 & 3 & 4 & 5 & 6 & 7 & 8 \\
\hline & \multicolumn{3}{|c|}{$\begin{array}{l}\text { Fluorescence in } \\
\text { galvanometer units }\end{array}$} & \multirow{2}{*}{$\begin{array}{l}\text { Time } \\
\text { to } \\
\text { maxi- } \\
\text { mum }\end{array}$} & \multicolumn{3}{|c|}{$\begin{array}{l}\text { Fluorescence in } \\
\text { galvanometer units }\end{array}$} & \multirow{2}{*}{$\begin{array}{c}\text { Time } \\
\text { to } \\
\text { maxi } \\
\text { mum }\end{array}$} \\
\hline & $\begin{array}{c}10 \\
\min \end{array}$ & $\begin{array}{l}\text { Maxi- } \\
\text { mum }\end{array}$ & $\begin{array}{l}\text { Decr. } \\
2 \text { hrs.* }\end{array}$ & & 10 & $\begin{array}{l}\text { Maxi- } \\
\text { mum }\end{array}$ & $\begin{array}{l}\text { Decr. } \\
2 \text { hrs.* }\end{array}$ & \\
\hline & $\begin{array}{l}8.5 \\
7.5 \\
4.5 \\
7.1 \\
4.0\end{array}$ & $\begin{array}{r}10.4 \\
9.0 \\
4.5 \\
7.1 \\
4.8\end{array}$ & $\begin{array}{l}9.5 \\
9.0 \\
4.5 \\
7.0 \\
3.7\end{array}$ & $\begin{array}{r}\min . \\
15 \\
19 \\
10 \\
9 \\
20\end{array}$ & $\begin{array}{l}0.6 \\
1.5 \\
1.5 \\
0.3 \\
0.2\end{array}$ & $\begin{array}{l}7.5 \\
5.5 \\
4.2 \\
3.5 \\
2.0\end{array}$ & $\begin{array}{l}2.7 \\
2.0 \\
0.8 \\
2.5 \\
1.5\end{array}$ & $\begin{array}{c}\text { min. } \\
70 \\
58 \\
54 \\
60 \\
84\end{array}$ \\
\hline \multicolumn{2}{|c|}{$\begin{aligned} \bar{X} & =6.78 \\
S E \bar{X} & =0.752\end{aligned}$} & & $\begin{array}{l}6.74 \\
1.163\end{array}$ & & $\begin{array}{l}0.82 \\
0.285\end{array}$ & & $\begin{array}{l}1.90 \\
0.344\end{array}$ & \\
\hline
\end{tabular}

$\bar{X}=$ Mean.

$S E_{\bar{X}}=$ Standard error of mean.

* Difference in galvanometer units between maximum readings and readings taken two hours after injection of fluorescein. Comparison of mean values at the base of columns 1 and 5 indicates difference in rate of entrance of dye in normal and frostbitten ears. Standard error of the difference between means of columns 1 and 5 is 1.213 and $P<0.01$ Comparison of columns 3 and 7 indicates difference in rate of exit of the dye Standard error of the difference between the two means is 0.804 and $P<0.001$. $P$ expresses the probability that such differences would be encountered by errors of random sampling. 
vessels also furnished evidence of rapid blood flow.

The fluorescence at 10 minutes, at the maximum, and the decrease in 2 hours following the injection of dye (see Table I) was greater in normal ears than in those injured by cold. Statistical comparison of the mean values for columns 1 and 5 showed a significant difference. Therefore, since the most rapid rate of entry of dye into frostbitten ears is significantly slower than the rate of entry into normal ears, the still slower rates of entry encountered at longer intervals after injury must also be lower than the rate in normal ears. The slowing of removal of dye from frostbitten ears as compared with the rates of removal from normal ears was found to be significant by means of a similar assessment of the difference between the means of values given in columns 3 and 7 . The data in columns 3 and 7 were obtained by subtracting from the galvanometer deflection measured at the peak of fluorescence, the galvanometer deflection measured 2 hours after the maximum was reached. The difference between these amounts of change over a period of 2 hours in the two groups is consistent with the marked difference in the general slopes of the curves of declining intensity of fluorescence. Progressive flattening of the curves is noted with increase in the interval between injury by cold and the injection of dye. Hence, the validity of the difference established between measurements on normal ears and on frostbitten ears tested immediately after frostbite may be presumed to extend to the greater differences observed at longer time intervals.

\section{The concentration of fluorescein in edema fluid and in blood}

In order to determine whether the delayed removal of fluorescein from frostbitten regions was a phenomenon restricted to layers of the skin near the surface or one involving the deeper layers also, analyses of blood and of edema fluid from frostbitten feet were made in three animals. One hind foot of each of three rabbits was frostbitten by immersion for 3 minutes in the freezing mixture at $-55^{\circ}$ C. (3). Intravenous injection of fluorescein, $75 \mathrm{mgm}$. per $\mathrm{kgm}$. body weight, was given at 10 minutes after frostbite. At intervals from 120
TABLE II

Comparison of fluorescein concentration in blood and edema fluid

$75 \mathrm{mgm}$. per $\mathrm{kgm}$. fluorescein given intravenously 10 minutes after exposure of one foot at $-55^{\circ} \mathrm{C}$. for 3 minutes

\begin{tabular}{|c|c|c|c|c|}
\hline $\begin{array}{l}\text { Animal } \\
\text { number }\end{array}$ & $\begin{array}{l}\text { Time after } \\
\text { fluorescein }\end{array}$ & $\begin{array}{l}\text { Blood } \\
\text { fluorescein } \\
\text { concen- } \\
\text { tration }\end{array}$ & $\begin{array}{c}\text { Plasma } \\
\text { fluorescein* } \\
\text { concen- } \\
\text { tration }\end{array}$ & $\begin{array}{l}\text { Edema fluid } \\
\text { fluorescein } \\
\text { concen- } \\
\text { tration }\end{array}$ \\
\hline & $\min$. & $\begin{array}{c}\text { mgm. per } \\
100 \mathrm{ml} .\end{array}$ & $\begin{array}{c}\text { mgm. per } \\
100 \text { ml. }\end{array}$ & $\begin{array}{c}\text { mgm. per } \\
100 \text { ml. }\end{array}$ \\
\hline $\begin{array}{l}78 \\
74 \\
81\end{array}$ & $\begin{array}{l}120 \\
140 \\
175\end{array}$ & $\begin{array}{l}1.78 \\
3.20 \\
0.20\end{array}$ & $\begin{array}{l}2.92 \\
5.25 \\
0.33\end{array}$ & $\begin{array}{r}5.10 \\
10.78 \\
8.25\end{array}$ \\
\hline
\end{tabular}

* Plasma fluorescein concentration calculated from whole blood fluorescein concentration assuming a hematocrit of 39 per cent (mean of 9 animals) and no penetration of fluorescein into red blood cells.

to 175 minutes after the injection of dye, samples of blood and of edema fluid were taken for fluorescein analysis. Data from these experiments are presented in Table II. The low concentrations of dye found in the blood of these animals is similar to that observed in normal animals at comparable times after fluorescein administration (2). Edema fluid, withdrawn from the frostbitten feet at the same time as the blood samples were obtained, contained dye at several times the concentration found in the blood. On the basis of an estimated hematocrit value of 39 per cent in rabbit No. 78, where the smallest difference is shown, the calculated plasma concentration of dye was $2.92 \mathrm{mgm}$. per $100 \mathrm{ml}$., only a little more than half of that in the edema fluid from the foot of the same animal.

\section{The influence of increased blood flow upon fluorescein exchanges in frostbitten rabbit ears}

Measurements of skin temperature in frostbitten ears and feet of rabbits have shown that the blood vessels of the injured regions do not participate in thermovascular reflex changes in diameter (4). However, the vessels of parts of ears proximal to the injured region show both tonic constriction and the ability to dilate in response to local application of heat or following procaine block of the stellate ganglions (6). The flow of blood into the injured area of frostbitten ears is, in part, determined by the degree of dilatation of the major arteries proximal to the line of frostbite. Direct observation of blood flow in frostbitten ears 
treated by rapid thawing in warm water or by procaine block of the stellate ganglion showed that the irreversible stage of stasis was delayed when blood flow was increased, whether the increase was brought about by heat or by sympathetic paralysis (6). If stasis was allowed to progress without treatment for 20 to 50 minutes, the subsequent increase of blood flow was ineffective in restoring movement of blood in true capillaries as determined by direct observation.

The influence of increased blood flow upon the distribution of fluorescein in the frostbitten ears of rabbits was tested in the following manner. Both ears of each of three rabbits were frostbitten by immersion for 1 minute in the freezing mixture at $-55^{\circ} \mathrm{C}$. At intervals varying from 54 to 125 minutes after frostbite, 1 to $2 \mathrm{ml}$. of 2 per cent procaine hydrochloride solution were injected into the region of the stellate ganglion on one side. Five minutes later fluorescein was in-

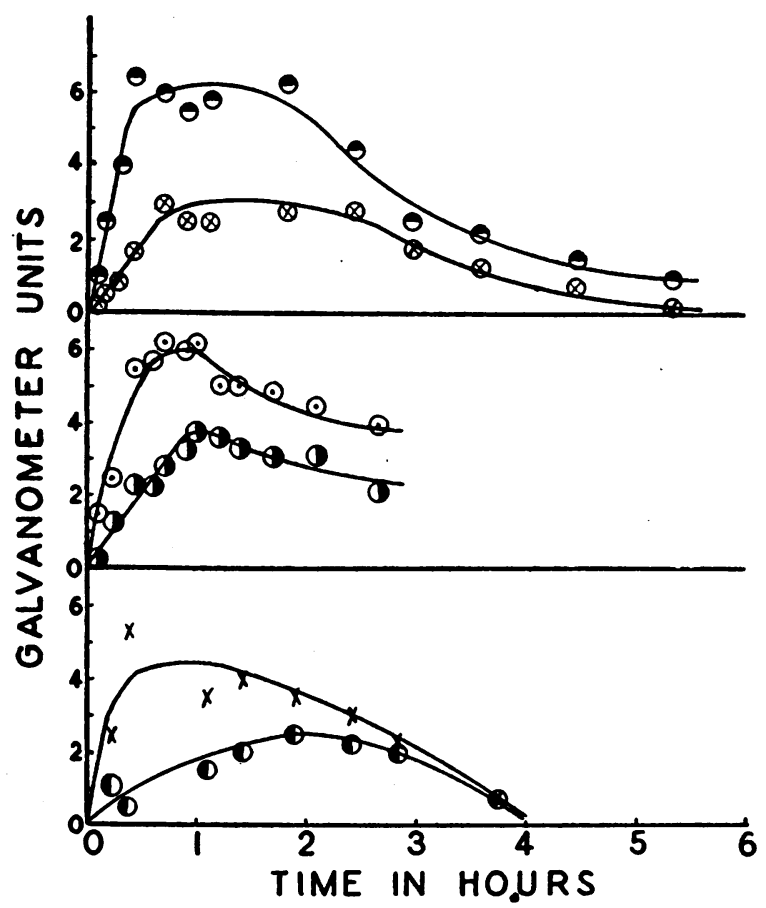

Fig. 3. Intensity of Fluorescence of Rabbits' Ears after Frostbite and Procaine Block of Right StelLate Ganglion

Both ears of each rabbit exposed at $-55^{\circ} \mathrm{C}$. for one minute. Procaine injected 2 hours after frostbite. Fluorescein injected 5 minutes after procaine (zero time on figure). Upper curves in each figure-right frostbitten ear, ganglion blocked. Lower curves in each figureleft frostbitten ear. Each figure represents one animal. jected by vein in the usual dose of $75 \mathrm{mgm}$. per kgm. body weight. Over the ensuing 2 to 6 hours, the intensity of fluorescence was measured in both ears. The curves presented in Figure 3 show that in all three animals the fluorescence of the ear on the side subjected to sympathetic block reached a higher maximum intensity than that measured on the injured, untreated ear. While the rate of increase in fluorescence was higher on the blocked side, the rate of removal was about the same for both.

The increase in fluorescence, observed in frostbitten ears under the circumstances described above, was measured at a time after injury when stasis in true capillaries was completely developed. Paralysis of the sympathetic nerve supply to the ear, at comparable times after injury in other experiments, had been found to be incapable of restoring blood flow in these vessels (6), even though the rise in skin temperature indicated an increased total blood flow. Since the exposure to cold of both ears in each animal was the same, the difference in intensity of fluorescence following procaine block of the stellate ganglion should be attributed to alteration of the minute volume or local pattern of blood flow rather than to differences in capillary permeability.

\section{DISCUSSION}

Observations of skin color, skin temperature, arterial pulsation, and movement of blood watched under the microscope, at least in some vascular channels, in the frostbitten ears of rabbits show that total blood flow is for a time greater than that in normal ears and does not become completely arrested until more than 50 hours after injury $(4,6)$. During the intervals characterized by rapid blood flow, tests with fluorescein show both delayed entrance and delayed exit of dye from the skin of the injured region. Lange's recently reported observations in which similar fluorescein tests were used upon accidental and experimental cold injury also point out the paradox of impaired dye exchange in the presence of good blood flow (1). He observed diminished fluorescence in regions injured by mild cold and was able to show that capillary blood obtained from poorly staining regions contained as much fluorescein as that from normal, brightly fluores- 
cent skin. Two possible explanations were offered to account for the differences observed: namely, that capillary permeability had decreased as the result of cold injury and that local vasoconstriction resulted in reduction of filtration pressure. The second of these explanations was considered to be a local change probably not involving more than axon reflexes, since the difference could not be abolished by local anesthesia or by sympathetic block. Severe cold, sufficient to freeze the tissues, resulted in delayed entrance of fluorescein and apparent hyperfluorescence when observations were made at successively longer intervals after dye injection.

The present studies on gangrene resulting from cold injury include several observations which are difficult to reconcile with Lange's assumption that reduced capillary permeability was the factor responsible for the abnormal distribution of fluorescein in tissues injured by cold. The rapid swelling of frostbitten parts, which begins virtually with the return of blood flow after thawing, and the high protein concentration of the edema fluid are changes not consistent with decreased capillary permeability. The delayed penetration of fluorescein into frostbitten regions also seems difficult to explain upon the basis of Lange's second suggestion, decreased filtration pressure, since this would have to coincide with the appearance of massive edema and the rise of subcutaneous tissue pressure to levels as high as $25 \mathrm{~cm}$. of water (7).

An attempt to explain the abnormal distribution of dye upon the basis of simple changes in capillary permeability would require the additional assumption that the permeability changes be selective with respect to the plasma constituents as well as to the direction of their free passage. If decreased capillary permeability were responsible for the delayed entrance of dye into the skin of the frostbitten region, the capillaries would have to be capable of passing large quantities of plasma protein into the interstitial fluid during the time that the loss of fluorescein from the blood in the same region was being restrained. Data presented in a previous report (7) furnish ample evidence of protein loss from the blood into the frostbitten ears and feet of rabbits.

Comparison between the fluorescence of frostbitten regions and the adjacent, uninjured areas at about 1 hour after the injection of dye shows that the glow from the injured region is much brighter than that from the normal area. This is an example of the "hyperfluorescence" of skin subjected to severe cold injury, described by Lange and Boyd (1). However, serial measurements made from the time of injection of dye furnish evidence on two important points: (a) the maximum brightness of the two areas does not coincide in time; and (b) the intensity of fluorescence at maximum for injured areas is lower than the maximum intensity reached in normal skin. Thus, what, on first inspection, might seem to be a hyperfluorescence of the injured area is actually less than the maximum intensity reached at an earlier time in normal skin. The appearance of hyperfluorescence is the result of removal of dye from adjacent uninjured areas at a faster rate than from the frostbitten area. This circumstance again poses the problem of apparently selective changes in permeability. If it be assumed that the hyperfluorescence is an expression of increased capillary permeability (1), then it must be a selective form of change in permeability, manifesting a decreased restraint of dye as it leaves the blood stream in the injured region and then failure of fluorescein to move into the capillaries when the diffusion gradient has become reversed by the decline of concentration of dye in the blood. Some form of permeability change, which is peculiarly selective with respect to particle size and which operates only in one direction, must be postulated to account for the facts. Such a postulate departs widely from the accumulated experience of investigators who have studied the nature of exchanges across capillary membranes $(8,9,10)$.

Both theoretical considerations (10) and measurements on normal animals (2) indicate that fluorescein should become distributed in a manner similar to that observed for other relatively small molecules, i.e., largely by diffusion. The major factors involved in such transfers of dissolved material include the diffusion gradient, the permeability of capillaries, the blood flow rate, and the surface area available for diffusion. The evidence presented above shows that the dye is slow in entering and still slower in leaving areas injured by severe cold. At the same time, other evidence indicates that the diffusion gradients, the minute 
volume blood flow, and the degree of capillary permeability are all such that faster rather than slower transfer of dye would be expected. As to possible alteration of the surface area available for diffusion, direct observation of blood flow in frostbitten, transilluminated ears of rabbits has shown that stasis begins early in the true capillaries and is complete within 10 minutes of the return of blood flow after thawing. Flow persists in arteriovenous anastomoses and arteriolarvenular capillaries. Since protein loss into the edema fluid is high in the early period and lower at later stages, it is not difficult to conceive of the early loss as occurring via abnormal leakage from these capillaries, which later are prevented from participating as exchange surfaces by having been blocked by silting red blood cells. Thus, blood flow persists at large minute volume and relatively high pressure in the channels remaining patent. This circumstance serves to explain both the rapid production of edema fluid by filtration and the interference with fluorescein distribution; there is a sharp reduction in the area available for diffusion. The dye, which is filtered out from the arteriorlar-venular capillaries, finds its way back into the blood stream, not by the usual reversal of gradient as the concentration of dye in the blood declines, but by slower removal via lymphatics and by movement of dye into adjacent uninjured regions where stasis has not occurred.

The above interpretation of phenomena observed in the aplication of fluorescein tests to the study of frostbite is consistent with other manifestations of altered blood flow and fluid exchange occurring after severe cold injury. Information about the degree of involvement of capillaries by stasis and its resolution may provide helpful guides in treatment and prognosis. Thus, in addition to the use of fluorescence as a clear-cut indicator of the presence or absence of blood flow, the estimation of rate of dye exchange in injured tissues may be of clinical value.

\section{SUM MARY}

Analyses were made of the distribution of intravenously injected fluorescein in normal ears of rabbits and in ears severely injured by cold. The results showed that both the dye's entrance into and its exit from the injured regions were slower than the exchanges observed in uninjured tissues.
The maximum intensity of fluorescence reached in frostbitten skin was lower than the maximum recorded in normal skin. Repeated tests on the same animal showed that the exchanges of dye became progressively slower with time after injury.

When both ears of rabbits were frostbitten and procaine block of the stellate ganglion was produced on one side, the tests with fluorescein showed earlier and higher maximum intensity of fluorescence in the frostbitten ear on the side blocked. This maneuver had been shown in other experiments to be followed by delay in the onset of stasis. The greater intensity of fluorescence on the side having increased blood flow as the result of blockage of the stellate ganglion was attributed to the longer persistence of blood flow through true capillaries and, hence, greater opportunity for exchange of dye between the blood and interstitial fluid.

Edema fluid was taken from frostbitten feet of rabbits at a sufficiently long interval after the intravenous injection of fluorescein to permit the concentration of dye in the blood to fall to very low levels. Analysis of the edema fluid showed that the fluorescein concentration was at least twice as great as that in the blood.

The mechanisms of impaired dye exchange in frostbitten tissues are discussed, and a hypothesis is presented in which the impairment of dye exchange is attributed to reduction of available surface for diffusion by the development of stasis in the true capillaries following cold injury.

\section{BIBLIOGRAPHY}

1. Lange, K., and Boyd, L. J., The functional pathology of experimental frostbite and the prevention of subsequent gangrene. Surg., Gynec. \& Obstet., $1945,80,346$.

2. Crismon, J. M., and Fuhrman, F. A., Studies on gangrene following cold injury. IV. The use of fluorescein as an indicator of local blood flow: distribution of fluorescein in body fluids after intravenous injection. J. Clin. Invest., 1947, 26, 259.

3. Fuhrman, F. A., and Crismon, J. M., Studies on gangrene following cold injury. I. A method for producing gangrene by means of controlled injury by cold. J. Clin. Invest., 1947, 26, 229.

4. Fuhrman, F. A., and Crismon, J. M., Studies on gangrene following cold injury. II. General course of events in rabbit feet and ears following untreated cold injury. J. Clin. Invest., 1947, 26, 236. 
5. Fisher, R. A., Statistical Methods for Research Workers. Ed. 6, Oliver and Boyd, London, 1936.

6. Crismon, J. M., and Fuhrman, F. A., Studies on gangrene following cold injury. VI. Capillary blood flow after cold injury. J. Clin. Invest., 1947, 26. (In press.)

7. Fuhrman, F. A., and Crismon, J. M., Studies on gangrene following cold injury. III. Edema following cold injury: its magnitude and the composition and source of edema fluid. J. Clin. Invest., 1947, 26, 245.
8. Zweifach, B. W., The structural basis of permeability and other functions of blood capillaries. Cold Spring Harbor Symp. Quant. Biol., 1940, 8, 216.

9. Danielli, J. R., and Stock, A., The structure and permeability of blood capillaries. Biol. Rev., 1944, $19,81$.

10. Teorell, T., Kinetics of distribution of substances administered to the body. II. The intravascular modes of administration. Arch. Internat. de Pharmacodyn. et de Thérap., 1937, 57, 226. 